\title{
Concentrações Plasmáticas de Progesterona e Metabólitos Lipídicos em Novilhas Mestiças Tratadas ou Não com Hormônio de Crescimento e Superovuladas ${ }^{1}$
}

\author{
Álan Maia Borges ${ }^{1}$, Ciro Alexandre Alves Torres ${ }^{2}$, José Reinaldo Mendes Ruas ${ }^{3}$, \\ Vicente Ribeiro Rocha Júnior ${ }^{1}$, Giovanni Ribeiro de Carvalho ${ }^{2}$, Juliana Corrêa Borges ${ }^{4}$
}

RESUMO - O objetivo do experimento foi estudar as concentrações plasmáticas de progesterona em novilhas mestiças, correlacionando-as com as concentrações de metabólitos lipídicos. Utilizaram-se 26 fêmeas divididas em dois tratamentos: T1 = aplicação de $500 \mathrm{mg}$ de sometribove zinco (somatotropina bovina recombinante) no terceiro dia do ciclo estral superovulado e T2 = controle. As coletas de sangue foram feitas durante dois ciclos estrais: normal e superovulado, e as análises de progesterona e dos metabólitos foram realizadas por radioimunoensaio e pelo método enzimático, respectivamente. O período experimental do ciclo estral superovulado foi dividido em três fases: $\mathrm{P} 1=$ do estro à inseminação artificial ( 0 ao $15^{\circ}$ dia $)$; P2 $=$ da inseminação artificial até a coleta de embriões $\left(15^{\circ}\right.$ ao $21^{\circ}$ dia $)$ e P3 = da coleta de embriões até o final do período $\left(21^{\circ}\right.$ ao $27^{\circ}$ dia $)$. Houve diferença nas concentrações de progesterona entre os animais dos dois tratamentos durante o P1, porém não diferiram nos P2 e P3. As concentrações plasmáticas de progesterona alcançaram valores superiores a $60 \mathrm{ng} / \mathrm{mL}$ após a superovulação. Os valores de colesterol total e de HDL foram diferentes entre os dois tratamentos, durante os períodos P2 e P3. Não houve correlações entre as concentrações plasmáticas dos metabólitos lipídicos e de progesterona durante os ciclos estrais estudados.

Palavras-chave: HDL, progesterona, somatotropina, superovulação, colesterol total

\section{Plasma Progesterone Concentrations and Lipidic Metabolites in Crossbred Holstein- Zebu Heifers Treated or not with Growth Hormone and Superovulated}

\begin{abstract}
The objective of this experiment was to study the progesterone plasma concentrations in crossbred heifers, and the correlation with lipid metabolites concentrations. Twenty-six heifers were distributed into two treatments: T1 - treated with 500 mg sometribove zinc (recombinant bovine somatotropin) on day 3 of superovulated estrous cycle and T2 - control. The blood samples were collected during two estrous cycles: normal and superovulated one. The progesterone and metabolic lipids concentrations were determined by RIA and enzymatic method, respectively. The experimental period of the superovulated estrous cycle was divided into three periods: $\mathrm{P} 1=$ from estrus to artificial insemination (0 to $15^{\text {th }}$ day); P2 - from artificial insemination to embryo collection $\left(15^{\text {th }}\right.$ to $21^{\text {st }}$ day) and P3 - from embryo collection to the end of the experiment $\left(21^{\text {st }}\right.$ to $27^{\text {th }}$ day). Plasma progesterone concentration differed between the two treatments during P1, but did not during P2 and P3. Progesterone concentration was greater than $60 \mathrm{ng} / \mathrm{mL}$ in superovulated heifers. The total plasma cholesterol and HDL concentrations were different between the two treatments, during P2 and P3. There were no correlations among the lipid metabolites and progesterone concentrations during the estrous cycles.
\end{abstract}

Key Words: HDL, progesterone, somatotropin, superovulation, total cholesterol

\section{Introdução}

A progesterona é um hormônio de importância primordial para a regulação do funcionamento do sistema reprodutor feminino e é produzida, principalmente, pelo corpo lúteo, advindo da reorganização das células foliculares após o processo ovulatório.

As concentrações plasmáticas de progesterona dos bovinos apresentam variações durante o ciclo estral normal, com concentrações abaixo de $1 \mathrm{ng} / \mathrm{mL}$ ao estro e valores máximos entre $2,3 \mathrm{ng} / \mathrm{mL}$ para vacas de raças zebuínas (AGARWAL et al., 1977) e $16,0 \mathrm{ng} / \mathrm{mL}$ em vacas da raça Holandesa (BADINGA et al., 1994) ao $10^{\circ}$ dia (ADEYEMO e HEATH,1980; JIMÉNEZ et al., 1988), que são mantidas elevadas até o início da regressão do corpo lúteo, caso não ocorra gestação.

Durante o ciclo estral, as variações na concentração de progesterona plasmática refletem a funcionalidade do corpo lúteo, entre sua fase de crescimento, de manutenção e de regressão. No dia do estro a progesterona está baixa. Após a ovulação, inicia-se a

\footnotetext{
${ }^{1}$ Aluno de Doutorado DZO/UFV. E.mail: alanmborges@hotmail.com; rochajuniorvr@hotmail.com

${ }^{2}$ Professor do DZO/UFV. E.mail: ctorres@mail.ufv.br; giovanni@mail.ufv.br

3 Pesquisador da EPAMIG/CTZM - Viçosa (MG). E.mail: jrmruas@mail.ufv.br

${ }^{4}$ Aluna de Mestrado DVT/UFV.
} 
reorganização tecidual com posterior aumento no fluxo sangüíneo ovariano e no peso do corpo lúteo (WILTBANK et al., 1995) e, conseqüentemente, aumentando a síntese de progesterona, que alcança valores máximos ao redor do $10^{\circ}$ dia (WISE et al., 1982), mantendo-se elevada durante o diestro. O início da regressão luteal é acompanhado por diminuição da vascularização e da secreção esteroidal, quando ocorre abrupta redução das concentrações de progesterona cerca de três dias antes do novo estro (VACA et al., 1983). Este fato também pode ser verificado na indução da luteólise após aplicação de agente luteolítico exógeno (LULAI et al., 1994).

Doadoras de embriões apresentaram correlação positiva entre o número de corpos lúteos e as concentrações plasmáticas de progesterona após o tratamento superovulatório (GOTO et al., 1988). As concentrações variaram de $2,1 \mathrm{ng} / \mathrm{mL}$, quando um corpo lúteo estava presente, até valores maiores que $56,7 \mathrm{ng} / \mathrm{mL}$ para um número de corpos lúteos superiores a 20 (MORRIS et al., 1988).

O colesterol é o substrato utilizado pelas células luteínicas para a síntese de progesterona e, nos bovinos, a lipoproteína de alta densidade (HDL) é a principal fonte deste metabólito (GRUMMER e CARROL, 1988), por ser esta, a mais abundante no plasma e no fluido folicular (GRUMMER e CARROL, 1991).

A concentração sérica de colesterol total em bovinos pode variar entre vacas $(172,8 \mathrm{mg} / \mathrm{dL}) \mathrm{e}$ novilhas $(121,4 \mathrm{mg} / \mathrm{dL}$ ) (ARAVE et al., 1974), e durante o ciclo estral apresentou padrão cíclico (TALAVERA et al., 1985) com redução durante a fase luteínica, que é o resultado, provavelmente, de sua utilização como substrato para a síntese de progesterona (CHRISTIE et al., 1979). O cultivo celular na presença de lipoproteínas HDL e LDL aumentou a produção de progesterona nas células luteais de vacas e ovelhas (CARROL et al., 1992).

A somatotropina bovina recombinante (rBST) regula os processos fisiológicos e metabólicos (DAVIS, 1998), por aumentar a síntese de IGF-I (fator de crescimento semelhante à insulina) e de proteínas transportadoras (IGFBP), que são os seus mediadores hormonais nos processos metabólicos (LUCY, 1996; COHICK, 1998). O rBST age nos ovários (TANNER e HAUSER, 1989) estimulando a síntese de IGF-I/IGFBP, controlando o desenvolvimento folicular, a função do corpo lúteo (LUCY et al., 1993; DEAVER e BRYAN, 1999) e das células da granulosa (LOBIE et al., 1990). Dentre diversos fatores e hormônios, o IGF-I tem papel importante no aumento da captação e absorção das lipoproteínas e na esteroidogênese pelas células da granulosa e tecido luteal (BUHR, 1987; VELDHUIS et al., 1986) e, dessa forma, pode estimular a síntese de progesterona pelo corpo lúteo.

Os objetivos deste experimento foram determinar o perfil plasmático de progesterona, durante um ciclo estral normal e após a superovulação de novilhas mestiças holandês-zebu, e verificar suas correlações com os metabólitos lipídicos: colesterol total e HDL.

\section{Material e Métodos}

O experimento foi realizado no Departamento de Zootecnia da Universidade Federal de Viçosa. Utilizaram-se 26 novilhas mestiças holandês-zebu com escore da condição corporal entre 4 e $5(1=$ muito magra, 5 = muito gorda) (segundo FERREIRA e TORRES, 1993) e peso vivo acima de $300 \mathrm{~kg}$, previamente selecionadas por exames clínico e ginecológico, acompanhadas por dois ciclos estrais completos, e mantidas estabuladas, onde receberam alimentação à base de feno de coastcross ( $7 \mathrm{~kg} / \mathrm{animal} /$ dia) e concentrado ( $3 \mathrm{~kg} / \mathrm{animal} / \mathrm{dia})$ à base de fubá de milho, farelo de soja, farelo de trigo e suplemento mineral vitamínico. Também, a água e sal mineralizado estiveram disponíveis à vontade, durante todo o período experimental. Os estros foram identificados duas vezes ao dia, pela manhã e à tarde, durante 1 hora, com o auxílio de rufião.

As doadoras de embriões foram acompanhadas durante um ciclo estral natural e, posteriormente, divididos em dois tratamentos (T1 e T2), em que $\mathrm{T} 1=13$ animais tratados com $500 \mathrm{mg}$ de somatotropina bovina recombinante (rBST) no $3^{\circ}$ dia do ciclo estral utilizado para a superovulação, e T2 $=13$ animais que não receberam $\mathrm{rBST}$ (controle). $\mathrm{O}$ tratamento superovulatório iniciou-se às $19 \mathrm{~h}$ do $10^{\circ}$ dia do ciclo estral $($ estro $=$ dia 0$)$, e estendeu-se por quatro dias, totalizando oito aplicações, em que se utilizaram 500 unidades internacionais (UI) de hormônio folículo estimulante/hormônio luteinizante ( $\mathrm{FSH} / \mathrm{LH})$, por via intramuscular, distribuído em doses decrescentes (100, $100,100,50,50,50,25,25 \mathrm{UI})$, com intervalos de 12 horas entre aplicações. Juntamente com a $7^{\mathrm{a}}$ dose do hormônio (130 dia, 19h), aplicou-se 0,5 mg de um análogo de prostaglandina $\mathrm{F}_{2} \alpha$ (cloprostenol), por via intramuscular. Após 24 horas desta aplicação, 
monitorou-se o estro até a identificação da primeira aceitação de monta, com inseminações artificiais sendo realizadas a intervalos de 12,18 e 24 horas após a detecção do estro, utilizando-se sêmen de qualidade comprovada. As coletas de embriões foram realizadas pelo método não cirúrgico, sete a oito dias após a primeira inseminação artificial, com lavagem simultânea dos cornos uterinos, utilizando-se solução comercial de PBS modificado (DULBECCO e VOGT, modificado por WHITTINGHAN, 1971) aquecido a $37^{\circ} \mathrm{C}$. Neste estudo administrou-se uma única dose de prostaglandina exógena $(0,5 \mathrm{mg}$ de cloprostenol) no dia da coleta, ao contrário da dose dupla normalmente usada na rotina de transferência de embriões, visando à luteólise dos corpos lúteos resultantes do processo superovulatório. Uma segunda dose foi administrada três dias após a primeira aplicação de prostaglandina.

As coletas de sangue para as dosagens de progesterona, colesterol total e de HDL tiveram início no dia do estro anterior ao ciclo estral utilizado para a superovulação (dia 0 ) e depois, a cada três dias e meio até o próximo estro. A partir do $3^{\circ}$ dia do ciclo estral utilizado para a superovulação, as amostras foram coletadas diariamente até o final do período experimental. Todas as coletas foram realizadas com tubos vacuolizados de $15 \mathrm{~mL}$ contendo solução anticoagulante (EDTA), por punção da artéria ou veia coccígea, e acondicionados em caixa de isopor com banho de gelo. Após centrifugação a $3000 \mathrm{rpm}$ (336,3 g) durante 15 minutos, separou-se o plasma, que foi acondicionado em tubetes plásticos, e estocado a uma temperatura de $-18^{\circ} \mathrm{C}$.

Para as análises de progesterona utilizou-se a metodologia de radioimunoensaio (RIA), e para o colesterol total e HDL o método enzimático, sendo utilizado "Kits" comerciais seguindo-se as recomendações dos fabricantes.

O período experimental correspondente ao ciclo estral utilizado para a superovulação foi dividido em três fases (P1, P2 e P3), onde P1= dia do estro até a inseminação artificial $\left(0\right.$ ao $15^{\circ}$ dia $) ; \mathrm{P} 2=$ do dia da inseminação artificial até o dia da coleta de embriões $\left(15^{\circ}\right.$ ao $21^{\circ}$ dia $)$ e $\mathrm{P} 3=$ da coleta de embriões até o final do experimento $\left(21^{\circ}\right.$ ao $\left.27^{\circ} \mathrm{dia}\right)$.

$\mathrm{Na}$ análise estatística utilizou-se o programa SAEG 7.0, aplicando-se análise de variância e regressão, a fim de comparar as concentrações de progesterona, tendo como fonte de variação os tratamentos e os dias de amostragem. Para os metabólitos colesterol total e HDL foi feita análise de variância e teste de F, para comparar as concentrações dos dois tratamentos. Os coeficientes de correlação entre a progesterona e os metabólitos lipídicos obtiveram-se pelo método de Pearson.

\section{Resultados e Discussão}

As concentrações médias de progesterona durante o ciclo estral normal das novilhas estão representadas na Figura 1 e demonstraram variação $(\mathrm{P}<0,01)$ entre os dias de amostragem (equação de regressão: $\hat{Y}=-0,604-0,206 D+0,663 D^{2}-0,0799 D^{3}$; $\left.\mathrm{R}^{2}=0,89\right)$. Estas foram mais baixas no dia do estro (menores que $0,3 \mathrm{ng} / \mathrm{mL}$ ), seguidas por um perfil ascendente até $012^{\circ}$ dia, com valores médios atingindo um máximo de $5,82 \mathrm{ng} / \mathrm{mL}$ do $9^{\circ}$ ao $15^{\circ}$ dia, e declinando bruscamente até concentrações basais no próximo estro.

Os dados obtidos estão de acordo com a literatura, onde são citadas concentrações plasmáticas de progesterona durante o diestro de ciclos estrais normais, entre 1 e 16 ng/mL (JIMÉNEZ et al., 1988; DÍAZ GONZÁLEZ, 1991; BADINGA et al., 1994) em animais de raças zebuínas e taurinas. Todavia, em novilhas mestiças, os valores podem chegar até a 20ng/mL (FERNANDES, 1994). Este padrão cíclico é devido à variação da funcionalidade do corpo lúteo (crescimento, manutenção e regressão). A secreção de progesterona aumenta até cerca do dia 10, mantém-

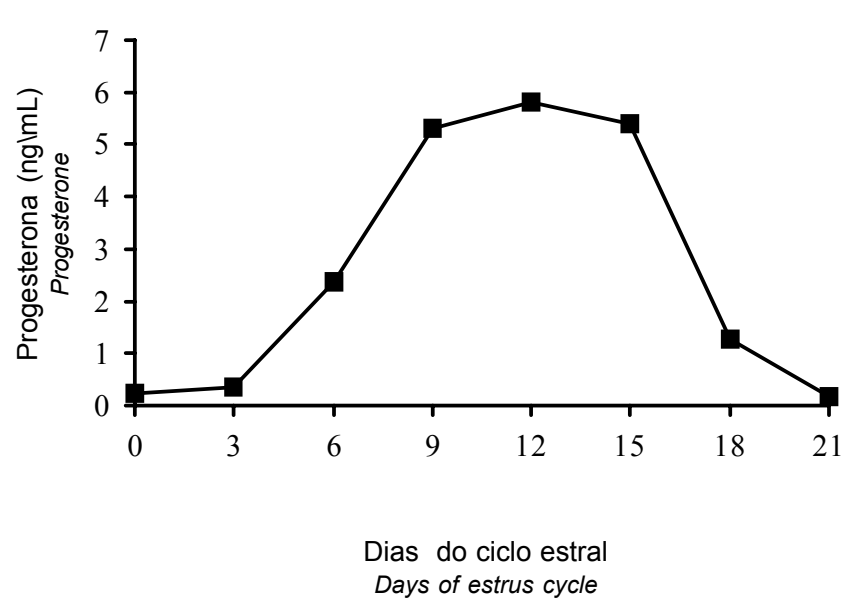

Figura 1 - Média das concentrações plasmáticas de progesterona em novilhas mestiças Holandêszebu, durante o ciclo estral natural.

Figure 1 - Mean plasma progesterone concentrations in Holsteinzebu crossbred heifers during the natural estrus cycle. 
se elevada durante o diestro e sofre abrupta redução três dias antes do novo estro (VACA et al., 1983).

Durante o P1 do ciclo superovulatório foi verificado perfil plasmático de progesterona semelhante ao do início de ciclo estral normal. Todavia, houve diferença nas concentrações entre os dois tratamentos $(\mathrm{P}<0,01)$ e entre os dias de amostragem $(\mathrm{P}<0,01)$, e são representados pelas seguintes equações de regressão: T1 $\left(\hat{\mathrm{Y}}=0,748-0,732 \mathrm{D}+0,254 \mathrm{D}^{2}-\right.$ $\left.0,0139 \mathrm{D}^{3} ; \mathrm{R}^{2}=0,94\right)$ e $\mathrm{T} 2(\hat{\mathrm{Y}}=0,239-0,336 \mathrm{D}+$ $\left.0,234 D^{2}-0,0144 D^{3} ; R^{2}=0,95\right)$. As concentrações de progesterona elevaram-se até o $12^{\circ}$ dia, e mantiveram-se elevadas até o $13^{\circ}$ dia, quando declinaram bruscamente a concentrações inferiores a $1 \mathrm{ng} / \mathrm{mL}$ (Figura 2). Esta queda é explicada pela luteólise induzida pela prostaglandina $\mathrm{F}_{2 \alpha}$ exógena (cloprostenol) aplicada no $13^{\circ}$ dia do tratamento superovulatório, e que culminou em novo estro utilizado para a realização das inseminações artificiais. Os maiores valores de progesterona para os animais do grupo controle (tratamento 2) podem ser devidos à menor variação nas concentrações deste hormônio, que foram mantidas acima da média dos animais do tratamento 1, durante o mesmo período. A

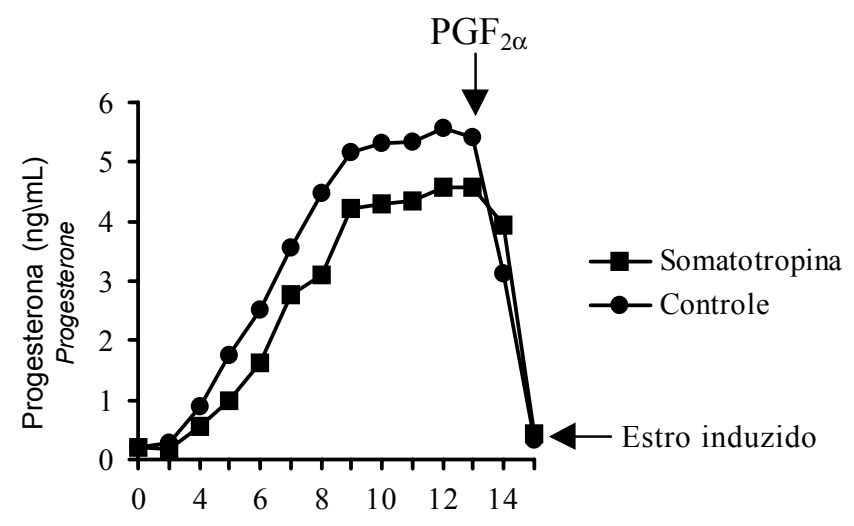

Dias do ciclo estral Days of estrus cycle

Figura 2 - Média das concentrações plasmáticas de progesterona entre o estro (dia 0) e a inseminação artificial de novilhas mestiças Holandês-zebu tratadas ( $\mathbf{\square})$ ou não $(\bullet)$ com somatotropina bovina recombinante no $3^{\circ}$ dia do ciclo estral e superovuladas.

Figure 2 - Mean plasma progesterone concentrations between estrus (day 0) and artificial insemination in Holsteinzebu crossbred heifers treated (घ) or not (•) with recombinant bovine somatotropin on day 3 of estrus cycle and superovulated. somatotropina aumenta o metabolismo e o fluxo sangüíneo hepático e, com isso, o clearance hormonal esteve aumentado (FOXCROFT et al., 2000), o que pode explicar a diferença observada nas concentrações de progesterona entre os animais dos dois tratamentos, com superioridade para aqueles pertencentes ao do grupo controle.

Após o estro induzido (P2) verificou-se aumento crescente nas concentrações plasmáticas de progesterona (Figura 3), observando-se diferenças para os dias de amostragem $(\mathrm{P}<0,01)$ mas não para os tratamentos, e foram representados pelas equações de regressão: T1 $\left(\hat{\mathrm{Y}}=-10,621+6,181 \mathrm{D} ; \mathrm{R}^{2}=0,95\right) \mathrm{e}$ $\mathrm{T} 2\left(\hat{\mathrm{Y}}=-13,055+6,724 \mathrm{D} ; \mathrm{R}^{2}=0,91\right)$. As concentrações médias foram superiores a $36 \mathrm{ng} / \mathrm{mL}$ no dia da coleta dos embriões (sétimo ou oitavo dia após a inseminação artificial), sendo que um animal apresentou valor superior a $90 \mathrm{ng} / \mathrm{mL}$. Este comportamento ascendente pode ser explicado pelo maior número de ovulações induzidas pelo tratamento superovulatório, que levou à formação de um grande número de corpos lúteos e, conseqüentemente, houve maior produção de progesterona. Esta correlação positiva entre número de corpos lúteos e progesterona plasmática

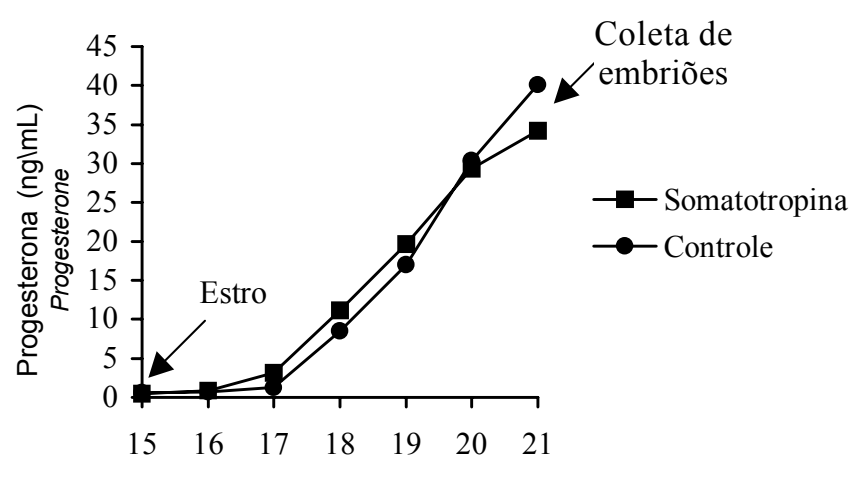

Dias do ciclo estral

Days of estrus cycle

Figura 3 - Média das concentrações plasmáticas de progesterona entre a inseminação artificial e a coleta de embriões de novilhas mestiças Holandês-zebu, superovuladas e tratadas (๘) ou não (•) com somatotropina bovina recombinante.

Figure 3 - Mean plasma progesterone concentrations between artificial insemination and embryo collection in Holsteinzebu crossbred heifers, superovulated and treated $(\square)$ or not (•) with recombinant bovine somatotropin. 
(GOTO et al., 1988) após a superovulação pode ser exemplificada pela produção de $2,1 \mathrm{ng} / \mathrm{mL}$ para um corpo lúteo, e de concentrações superiores a $56,7 \mathrm{ng} / \mathrm{mL}$ para um número de corpos lúteos superior a 20 (MORRIS et al., 1988).

Estas elevadas concentrações de progesterona são função direta da massa do tecido luteínico e do número de corpos lúteos funcionais presentes nos ovários (MORRIS et al., 1988; GOTO et al., 1988; FERNANDES, 1994).

A terceira fase (P3), caracterizada por diferenças $(\mathrm{P}<0,01)$ entre os dias de amostragem e sem diferença $(\mathrm{P}>0,05)$ para os tratamentos, pode ser representada pelas equações de regressão: $\mathrm{T}^{1}\left(\hat{\mathrm{Y}}=70,285-48,469 \mathrm{D}+10,533 \mathrm{D}^{2}-0,723 \mathrm{D} 3 ; \mathrm{R}^{2}=0,96\right)$ e $\mathrm{T}^{2}\left(\hat{\mathrm{Y}}=82,338-58,327 \mathrm{D}+12,920 \mathrm{D}^{2}-0,899 \mathrm{D}^{3}\right.$; $\left.\mathrm{R}^{2}=0,94\right)$. A Figura 4 mostra redução brusca nas concentrações de progesterona entre o dia da coleta dos embriões e o final do período experimental.

Neste estudo verificou-se que a administração de dose única de prostaglandina (0,5 mg de cloprostenol) praticamente reduziu as concentrações de progesterona a $1 \mathrm{ng} / \mathrm{mL}$ (Tabela 1), ou seja, valor abaixo do qual já é possível a manifestação de um novo estro (JIMÉNEZ et al.,1988).

As concentrações plasmáticas médias dos metabólitos lipídicos colesterol total e HDL, durante o ciclo estral normal e no ciclo superovulado, estão contidas na Tabela 2.

As concentrações de colesterol total e HDL não diferiram $(\mathrm{P}>0,05)$ entre os dois tratamentos para os diferentes períodos de amostragens, durante o ciclo estral normal (não submetidos a qualquer tratamento) e durante a fase $\mathrm{P} 1$ do ciclo superovulatório. Contudo, houve diferença $(\mathrm{P}<0,01)$ entre os dois tratamentos,

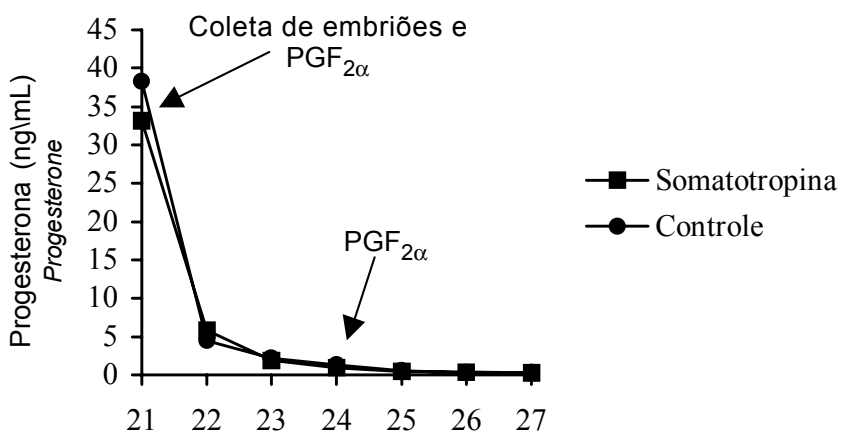

Dias do ciclo estral Days of estrus cycle

Figura 4 - Média das concentrações plasmáticas de progesterona entre o dia da coleta de embriões e o final do período experimental, de novilhas mestiças Holandês-zebu, superovuladas e tratadas ( $\mathbf{\square})$ ou não $(\bullet)$ com somatotropina bovina recombinante.

Figure 4 - Mean plasma progesterone concentrations between embryo collection and the end of experimental period in Holstein-zebu crossbred heifers superovulated and

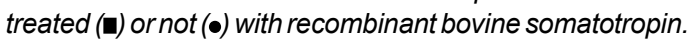

durante as fases P2 e P3 (Tabela 2), sem haver diferenças entre os dias de amostragens. Os valores encontrados para colesterol total estão de acordo com os dados da literatura, que citam concentrações em bovinos variando de 80 a $120 \mathrm{mg} / \mathrm{dL}$ (ARAVE et al., 1974; TALAVERA et al., 1985; SMITH, 1992). Todavia, as concentrações de HDL foram inferiores aos $68 \mathrm{mg} / \mathrm{dL}$ encontrados por MÂNCIO (1994) e aos $77,7 \mathrm{mg} / \mathrm{dL}$ de OLIVEIRA (1995) em estudos realizados com novilhas.

As diferenças observadas entre os dois tratamentos

Tabela 1 - Médias das concentrações plasmáticas de progesterona após a aplicação da primeira e segunda doses de prostaglandina $F_{2 \alpha}$ em novilhas mestiças Holandês-zebu tratadas ou não com somatotropina bovina recombinante no terceiro dia do ciclo superovulatório

Table 1 - Mean plasma progesterone concentrations after first and second prostaglandin injection in Holstein-zebu crossbred heifers, treated or not with recombinant bovine somatotropin on day 3 of superovulated estrus cycle

\begin{tabular}{ccc}
\hline $\begin{array}{l}\text { Dias após a coleta de embriões } \\
\text { Days after embryo collection }\end{array}$ & $\begin{array}{c}\text { Concentração plasmática de progesterona } \\
\text { Plasma progesterone concentration }(\mathrm{ng} / \mathrm{mL})\end{array}$ & $\begin{array}{c}\text { Dia da aplicação da } \mathrm{PGF}_{2 \alpha} \\
\text { Day of } P \mathrm{FF}_{2 \alpha} \text { injection }\end{array}$ \\
\hline $\begin{array}{c}\text { Coleta de embriões } \\
\text { Embryo collection }\end{array}$ & 36,4 & \\
1 & 4,1 & \\
2 & 2,0 & \\
3 & 1,2 & \\
4 & 0,5 & \\
5 & 0,5 & \\
6 & 0,4 & \\
\hline
\end{tabular}


Tabela 2 - Médias das concentrações plasmáticas de colesterol total e de HDL durante o ciclo estral de novilhas mestiças Holandês-zebu tratadas ou não com somatotropina bovina recombinante no terceiro dia do ciclo superovulatório

Table 2 - Mean plasma concentrations of total cholesterol and HDL during the estrous cycle in Holstein-zebu crossbred heifers, treated or not with recombinant bovine somatotropin on day 3 of superovulated estrus cycle

\begin{tabular}{|c|c|c|c|c|}
\hline \multirow[t]{2}{*}{$\begin{array}{l}\text { Fase } \\
\text { Phase }\end{array}$} & \multicolumn{2}{|c|}{$\begin{array}{c}\text { Colesterol total }(\mathrm{mg} / \mathrm{dL}) \\
\text { Total cholesterol }\end{array}$} & \multicolumn{2}{|c|}{$\mathrm{HDL}(\mathrm{mg} / \mathrm{dL})$} \\
\hline & $\begin{array}{l}\text { Somatotropina } \\
\text { Somatotropin }\end{array}$ & $\begin{array}{c}\text { Controle } \\
\text { Control }\end{array}$ & $\begin{array}{l}\text { Somatotropina } \\
\text { Somatotropina }\end{array}$ & $\begin{array}{l}\text { Controle } \\
\text { Controle }\end{array}$ \\
\hline $\begin{array}{l}\text { Ciclo estral normal } \\
\text { Normal estrus cycle }\end{array}$ & $87,9 \pm 13,8$ & $85,9 \pm 11,9$ & $25,8 \pm 5,2$ & $26,7 \pm 5,6$ \\
\hline $\begin{array}{l}\text { P1 } \\
\text { P2 }\end{array}$ & $\begin{array}{l}88,0 \pm 16,1 \\
88,5 \pm 14,5^{\mathrm{a}}\end{array}$ & $\begin{array}{l}85,6 \pm 17,8 \\
81,8 \pm 16,7^{b}\end{array}$ & $\begin{array}{l}28,7 \pm 6,7 \\
29,0 \pm 5,3^{c}\end{array}$ & $\begin{array}{l}27,7 \pm 4,6 \\
27,1 \pm 5,0^{d}\end{array}$ \\
\hline $\mathrm{P} 3$ & $88,0 \pm 13,1$ & $80,5 \pm 17,6^{\mathrm{b}}$ & $30,4 \pm 5,3^{\mathrm{c}}$ & $26,6 \pm 5,4^{\mathrm{d}}$ \\
\hline
\end{tabular}

a,b,c,d Valores seguidos por letras minúsculas distintas dentro da mesma linha diferem $(P<0,01)$ pelo teste $F$.

$a, b, c, d \quad$ Values with different superscripts within rows differ $(P<.01)$ by $F$ test.

podem ser devidas ao efeito da aplicação de somatotropina bovina recombinante (rBST) nos animais do tratamento 1 . O hormônio de crescimento $(\mathrm{GH})$ é um dos hormônios que regulam o metabolismo orgânico e possui diversas funções, dentre as quais, é responsável pelo aumento da lipólise e diminuição da lipogênese (MATOS, 1998). Deste modo, a maior mobilização das reservas de gordura induzida pela somatotropina exógena pode conduzir a uma via metabólica alternativa, elevando as concentrações plasmáticas de colesterol total e, conseqüentemente, de HDL.

O comportamento das concentrações plasmáticas de progesterona e de metabólitos lipídicos obtidas neste trabalho contradizem os achados de TALAVERA et al. (1985) e MÂNCIO (1994), que verificaram declínio nas concentrações de colesterol durante a fase luteal de novilhas em boa condição corporal e alimentadas com dieta normal. Para O'SHAUGHNESSY e WATHES (1985) e GRUMMER e CARROL (1988) a redução dos metabólitos pode ser resultado da captação das lipoproteínas (HDL) pelo tecido luteal para a síntese de progesterona. Todavia, neste experimento, a pouca variação diária nas concentrações de colesterol total e de HDL, independente do ciclo estral estudado (normal ou superovulado), sugere que não houve redução nas concentrações plasmáticas destes metabólitos com o aumento da síntese de progesterona (ciclo normal = $5,0 \mathrm{ng} / \mathrm{mL}$; ciclo superovulado $=39,0 \mathrm{ng} / \mathrm{mL}$ ). Se assim ocorresse, durante a superovulação, quando foi formado um grande número de corpos lúteos, as concentrações de colesterol deveriam ter diminuído proporcionalmente, fato que não foi observado. Isto pode ser verificado por meio dos baixos coeficientes de corre- lação de Pearson $(<0,14)$ entre as concentrações de progesterona e dos metabólitos lipídicos (Tabela 3).

Tabela 3 - Correlações simples de Pearson entre as concentrações plasmáticas de progesterona, colesterol total e HDL em novilhas mestiças Holandês-zebu doadoras de embriões

Table 3 - Pearson correlation between plasma progesterone concentrations and total cholesterol and HDL, in Holstein-zebu crossbred heifers donors of embryos

\begin{tabular}{cc}
\hline $\begin{array}{c}\text { Progesterona } \\
\text { Progesterone }\end{array}$ & $\begin{array}{c}\text { Colesterol total } \\
\text { Total cholesterol }\end{array}$ \\
\hline
\end{tabular}

Ciclo estral normal

Normal estrus cycle

Colesterol total

Total cholesterol

HDL

Estro até a inseminação

artificial

From estrus to artificial

insemination

Colesterol total

Total cholesterol

HDL

I.A. até coleta de

embriões

Artificial insemination to

embryo collection

Colesterol total

Total cholesterol

HDL

Coleta ao final do

experimento

Embryo collection to

the end of experiment

Colesterol total

Total cholesterol

HDL

$0,008^{*}$

$$
0,05^{*}
$$

$0,49 * *$

${ }^{*} \mathrm{P}>0,05 ;{ }^{* *} \mathrm{P}<0,01$. 


\section{Conclusões}

As concentrações plasmáticas de progesterona apresentaram variações em função do dia do ciclo estral, com valores superiores a $60 \mathrm{ng} / \mathrm{mL}$ em animais superovulados.

A somatotropina bovina alterou as concentrações plasmáticas de progesterona durante a primeira fase do ciclo estral utilizado para a superovulação, sem modificá-las durante a segunda e terceira fase. As concentrações de colesterol total e de HDL foram alteradas pelo tratamento com rBST durante estas duas últimas fases de avaliação.

A elevação das concentrações progesterona após o tratamento superovulatório não foi acompanhada por redução das concentrações de colesterol total e de HDL, o que demonstra ausência de correlação com as variações cíclicas da progesterona plasmática.

\section{Agradecimento}

Às seguintes empresas, pela doação de seus produtos: Mallinckrodt Veterinary - Coopers do Brasil Ltda. (Ciosin); Fisons Industrial Ltda. (Anestésico PEARSON); Laboratórios Calier do Brasil Ltda (Pluset); Nutricell - Nutrientes Celulares (Soluções para congelamento de embriões e DPBS 0,4\% BSA); Cultilab (Dulbecco Modificado - DPBS e Soro fetal bovino); Tortuga (Bovigold); Sembra (Sêmen); Vallée (Aldazol Co e Controller CTO Pour On).

\section{Referências Bibliográficas}

ADEYEMO, O., HEATH, E. 1980. Plasma progesterone concentration in Bos taurus and Bos indicus heifers. Theriogenology, 14(6):411-420.

AGARWAL, S.P., RAHMAN, S.A., LAUMAS, K.R. et al. 1977. Studies on steroid hormones: Progesterone concentration in the blood serum of zebu cows during oestrous cycle. Indian J. Anim. Sci., 47(11):715-719.

ARAVE, C.W., MILLER, R.H., LAMB, R.C. 1974.Genetic and environmental effects on serum cholesterol of dairy cattle of various ages. J. Dairy Sci., 58(3):423-427.

BADINGA, L., THATCHER, W.W., WILCOX, C.J. et al. 1994. Effect of season on follicular dynamics and plasma concentrations of estradiol-17 $\beta$, progesterone and luteinizing hormone in lactating Holstein cows. Theriogenology, 42:1263-1274.

BUHR, M.M. 1987. Effect of lipoproteins and luteinizing hormone on progesterone production by large and small luteal cells throughout the porcine estrus cycle. J. Anim. Sci., 65:1027-1031.

CARROL, P.J., GRUMMER, R.W., MAO, F.C. 1992. Progesterone production by cultured luteal cells in the presence of bovine low and high density lipoproteins purified by heparin affinity chromatography. J. Anim. Sci., 70(8):2516-2526.
CHRISTIE, M.H., STRAUSS, J.F., FLICKINGER, G.L. 1979. Effect of reduced blood cholesterol on sterol and steroid metabolism by rat luteal tissue. Endocrinology, 105:92-98.

COHICK, W.S. 1998. Role of insulin-like growth factors and their binding proteins in lactation cows. J. Dairy Sci., 81:1769-1777.

DAVIS, S.L. 1998. Recent concepts in regulation of growth by GH and IGF. J. Anim. Sci., 66 (supl. 3):84-97.

DEAVER, D.R., BRYAN, K.A. 1999. Effects of exogenous somatotropin (ST) on gonadal function in ruminants and swine. Dom. Anim. Endocr., 17:287-297.

DÍAZ GONZÁLEZ, F.H. Efeito da condição corporal de novilhas sobre a fertilidade, o perfil metabólico pós-serviço e a sobrevivência embrionária. Viçosa, MG: UFV, 1991. 118p. Tese (Doutorado em Zootecnia) - Universidade Federal de Viçosa, 1991.

FERNANDES, C.A.C. Efeito do tratamento com hormônio foliculo estimulante (FSH) sobre a taxa de gestação de novilhas mestiças usadas como receptoras de embrião. Viçosa, MG: UFV, 1994. 63p. Dissertação (Mestrado em Zootecnia) - Universidade Federal de Viçosa, 1994.

FERREIRA, A.M., TORRES, C.A.A. 1993. Perda de peso corporal e cessação da atividade ovariana luteínica em vacas mestiças leiteiras. Pesq. Agropec. Bras., 28:411-418.

FOXCROFT, G., ALMEIDA, F., AHERNE, F. Management of the gilt and first parity sow: Part IV. Nutritional management of gilts at breeding. In: VII Simpósio Internacional de Reprodução e Inseminação Artificial em Suínos. Anais... Foz do Iguaçu: PR, p. 131-145, 2000.

GOTO, K., OHKUTSU, S., NAKANISHI, Y. et al. 1988. Endocrine profiles and embryo quality in superovulated japanese black cattle. Theriogenology, 29(3):615-629.

GRUMMER, R.R., CARROL, D.J. 1988. A review of lipoprotein cholesterol metabolism: importance to ovarian function. J. Anim. Sci., 66:3160-3173.

GRUMMER, R.R., CARROL, D.J. 1991. Effects of dietary fat on metabolic disorders and reproductive performance of dairy cattle. J. Anim. Sci., 69:3838-3852.

JIMÉNEZ, F., GALINA, C.S., DUCHATEAU, A. et al. 1988. Levels of $\mathrm{LH}$, progesterone and estradiol-17 $\beta$ during natural and $\mathrm{PGF}_{2 \alpha}$ induced estrus in Indubrazil and Brown Swiss cows in the tropics. Anim. Reprod. Sci., 16:199-206.

LOBIE, P.E., BREIPOHL, W., ARAGON, J.G. et al. 1990. Cellular localization of the growth hormone receptor/binding protein in the male and female reproductive systems. Endocrinology, 126:2214-2221.

LUCY, M.C. Use of bovine somatotropin to increase follicular growth in cattle: Applications to superovulation. In: ANNUAL CONVENTION OF AMERICAN EMBRYO TRANSFER ASSOCIATION, 15, Portland, Oregon, 1996. Proceedings... Portland, 1996. p.61-70.

LUCY, C.M., COLLIER, R.J., KITCHELL, M.L. et al. 1993. Immunohistochemical and nucleic acid analysis of somatotropin receptor populations in the bovine ovary. Biol. Reprod., 48:1219-1227.

LULAI, C., KASTELIC, J.P., CARRUTHERS, T.D. 1994. Role of luteal regression in embryo death in cattle. Theriogenology, 41:1081-1089.

MÂNCIO, A.B. Plano nutricional, gonadotrofina coriônica humana (hCG) e amamentação na função reprodutiva e metabólica de fêmeas bovinas. Viçosa, MG: UFV, 1994. 158p. Tese (Doutorado em Zootecnia) - Universidade Federal de Viçosa, 1994. 
MATOS, W. Somatotropina na pecuária de leite e corte. In: REUNIÃO ANUAL DA SOCIEDADE BRASILEIRA DE ZOOTECNIA, 35, 1998, Botucatu. Anais... Botucatu, 1998, p.35-52.

MORRIS, C.A., DAY, A.M., PETERSON, A.J. 1988. An experiment to measure the dose-response relationship of ovulation rate to FSH in cows selected with history of twinning. New Zealand Vet. J., 36:189-191.

OLIVEIRA, F.N. Concentrações sangüineas de progesterona e metabólitos lipídicos em novilhas tratadas com Norgestomet e Valerato de estradiol (Syncro-Mate B) e submetidas à dieta hiperlipidêmica. Viçosa, MG:UFV, 1995. 75p. Dissertação (Mestrado em Zootecnia) - Universidade Federal de Viçosa, 1995.

O'SHAUGHNESSY, P., WATHES, D.C. 1985. Roles of lipoproteins and de novo cholesterol synthesis in progesterone production by bovine luteal cells. J. Reprod. Fertil., 74:425-432.

SMITH, B.P. 1992. Tratado de medicina interna de grandes animais. São Paulo: Editora Manole. 1661p.

TALAVERA, F., PARK, C.S., WILLIAMS, G.L. 1985. Relationships among dietary lipid intake, serum cholesterol and ovarian function in Holstein heifers. J. Anim. Sci., 60(4):1045-1051.
TANNER, J.W., HAUSER, S.D. 1989. Molecular evidence for the presence of the somatotropin receptor in the bovine ovary. J. Anim. Sci., 67 (suppl 1):413 (abst. 1001).

VACA, L.A., GALINA, C., FERNÁNDEZ-BACA, S. et al. 1983. Progesterone levels and relationship with the diagnosis of a corpus luteum by rectal palpation during the estrous cycle in zebu cows. Theriogenology, 20(1):67-76.

VELDHUIS, J.D.E., NESTLER, J.E., STRAUSS, J.F. et al. 1986. Insulin regulates low-density lipoprotein metabolism by swine granulosa cells. Endocrinology, 118(2):242-248.

WHITTINGHAN, D.G. 1971. Culture of mouse ova. J. Reprod. Fertil., 48 (suppl.14):7-21.

WILTBANK, M.C., SHIAO, T.F., BERGFELT, D.R. et al. 1995. Prostaglandin $\mathrm{F}_{2 \alpha}$ receptors in the early bovine corpus luteum. Biol. Reprod., 52:74-78.

WISE, T.H., CATON, D., THATCHER, W.W. et al. 1982. Ovarian function during the estrous cycle of the cow: ovarian blood flow and progesterone release rate. J. Anim. Sci., 55(3):627-637. 